\title{
Review of analytical performance of COVID-19 detection methods
}

\author{
Basant Giri ${ }^{1} \cdot$ Shishir Pandey ${ }^{1} \cdot$ Retina Shrestha $^{1} \cdot$ Krisha Pokharel $^{1} \cdot$ Frances S. Ligler $^{2} \cdot$ Bhanu B. Neupane $^{1,3}$
}

Received: 2 July 2020 / Revised: 11 August 2020 / Accepted: 14 August 2020 / Published online: 18 September 2020

(C) The Author(s) 2020

\begin{abstract}
In the recent SARS-CoV-2 pandemic, public health experts have emphasized testing, tracking infected people, and tracing their contacts as an effective strategy to reduce the spread of the virus. Several diagnostic methods are reported for detecting the coronavirus in clinical, research, and public health laboratories. Some tests detect the infection directly by detecting the viral RNA and other tests detect the infection indirectly by detecting the host antibodies. A diagnostic test during the pandemic should help make an appropriate clinical decision in a short period of time. Recently reported diagnostic methods for SARS-CoV-2 have varying throughput, batching capacity, requirement of infrastructure setting, analytical performance, and turnaround times ranging from a few minutes to several hours. These factors should be considered while selecting a reliable and rapid diagnostic method to help make an appropriate decision and prompt public health interventions. This paper reviews recent SARS-CoV-2 diagnostic methods published in journals and reports released by regulatory agencies. We compared the analytical efficiency including limit of detection, sensitivity, specificity, and throughput. In addition, we also looked into ease of use, affordability, and availability of accessories. Finally, we discuss the limitations of the methods and provide our perspectives on priorities for future test development.
\end{abstract}

Keywords Coronavirus $\cdot$ SARS-CoV-2 $\cdot$ COVID-19 $\cdot$ RT-PCR $\cdot$ Immunoassays $\cdot$ Disease diagnosis

\section{Introduction}

The coronavirus disease 2019 (COVID-19) follows multiple past epidemics caused by highly transmissible respiratory viral infections. COVID-19 is caused by the severe acute respiratory syndrome coronavirus 2 (SARS-CoV-2) that was first reported in Wuhan, China [1], and spread into a public health emergency worldwide. Public health experts have emphasized testing as many individuals as possible, tracking infected people, and tracing their contacts as an effective strategy to reduce the spread of the virus. Most of the governments across the globe are

Frances S. Ligler

fsligler@ncsu.edu

1 Center for Analytical Sciences, Kathmandu Institute of Applied Sciences, Kathmandu 44600, Nepal

2 Joint Department of Biomedical Engineering, University of North Carolina at Chapel Hill and North Carolina State University, Raleigh, NC 27695, USA

3 Central Department of Chemistry, Tribhuvan University, Kathmandu 44618, Nepal exercising this practice to variable extent using an array of testing methods.

The SARS-CoV-2 is a positive-sense single-stranded RNA $\beta$ family coronavirus that is genetically similar to SARS coronavirus and bat SARS-like coronaviruses [2]. Each virion is 50-200 nm in diameter and consists of four structural proteins named as S (spike), E (envelope), M (membrane), and N (nucleocapsid). The $\mathrm{N}$ protein holds the RNA genome of the virus and $\mathrm{S}, \mathrm{E}$, and $\mathrm{M}$ proteins create the virus envelope together [3]. Recent studies have suggested that bats may be the potential natural host of SARS-CoV-2 [4, 5] and Malayan pangolin the potential intermediate host [6].

Several diagnostic methods have been used to detect the coronavirus in clinical, research, and public health laboratories. Direct tests detect the infection directly by detecting the viral RNA, while indirect tests measure antibodies against the virus in a host that has been exposed. A diagnostic test method should have sufficient sensitivity and accuracy to make appropriate clinical decisions rapidly during a pandemic [7].

Nucleic acid amplification using the reverse transcription polymerase chain reaction (RT-PCR) is the most widely used method for direct SARS-CoV-2 diagnosis [7]. Immunoassays are used to measure the antibodies against the SARS-CoV-2. Emerging methods utilizing CRISPR (clustered regularly 
interspaced short palindromic repeats) have also been reported, even to the extent of incorporating such tests into nanoparticle-based biosensors. Apart from laboratory-based RT-PCR and immunoassay, several point-of-care (POC) and rapid test methods have become available in the last few months. The major diagnostic methods are illustrated in Fig. 1 and Table 1. Regulatory agencies such as the World Health Organization (WHO) and the US Food and Drug Administration (FDA) have approved the use of a number of diagnostic methods, while some new methods are receiving conditional approval under emergency use authorization (EUA) [22]. These diagnostic methods have varying throughput, batching capacity, requirement of infrastructure setting, analytical performance, and turnaround times [7]. In addition to depending on the equipment and method itself, the result from a method also relies on sample collection protocol, reagents used, potential for cross-contamination, and sample/ reagent storage requirements. These factors must be considered while selecting a reliable and rapid diagnostic method to help make an appropriate decision and prompt public health actions.

In this paper, we review recently published SARS-CoV-2 diagnosis methods and compare their analytical efficiency in terms of limit of detection (LOD), sensitivity, specificity, and throughput. In addition, we also evaluated ease of use, affordability, and availability of accessories. Note that other tests from a wide variety of companies are being used for COVID-19 diagnostics, with additional products entering the market each week; however, in the rush to get the tests operational, the information on these critical parameters and the company-unique information are often not yet published. Finally, we discuss the limitations of the methods and provide our perspective on priorities for future test development. The intended audience for this paper are students and researchers working on method development and clinical testing of viruses including SARS-CoV-2. People who make decision on which test method should be recommended to a clinical laboratory for the diagnosis of COVID-19 will also benefit from this review paper.

\section{Sample collection}

Two types of sample specimens are being primarily used for the diagnosis of COVID-19. Respiratory specimens are used for direct detection of virus and serum samples are used for identification of antiviral antibodies [23]. Direct detection of viral RNA in wastewater samples is also being used for community surveillance [24]. Similarly, saliva and stool samples have also been explored and require less challenging sampling procedures than respiratory specimens [25]. The respiratory specimens [26] are collected most frequently from the upper respiratory tract (e.g., nasopharynx or oropharynx) and less frequently from the lower respiratory tract (e.g., bronchoalveolar lavage fluid (BLF)). The upper respiratory specimens are collected in the acute phase of infection-ideally within 7 days. Lower respiratory specimens are obtained from patients still symptomatic after more than a week [27, 28]. Apart from nasal and throat specimens, sputum specimens are also collected for the diagnosis of COVID-19 by expectorating deep cough into a sterile container [28]. Serum samples are collected for immunoassay methods. Volume of blood sample for immunoassays ranges from 5 to $10 \mathrm{~mL}$ for lab assays to capillary draws of 50-200 $\mu \mathrm{L}$ blood for lateral flow immunoassays (LFIA) [29].

The virus samples should be processed and tested as soon as possible. If immediate testing is not possible, the sample can be stored up to $72 \mathrm{~h}$ at $2-8^{\circ} \mathrm{C}$. However, for more than 72 $\mathrm{h}$ storage, the specimens should be frozen at $-70^{\circ} \mathrm{C}$ as soon as possible after collection [28]. It is recommended to avoid repeated freezing and thawing of the specimen [30].

The right type of sample, appropriate collection procedure, and reliable transportation must be in place to minimize the risk of inaccurate results. Based on the stage of infection on a person and the purpose of test, an appropriate sample should be collected. Higher viral loads of SARS-CoV-2 have been reported from specimens collected from nose than from throat [31]. Similarly, higher positive rates were found with nasopharyngeal swabs than oropharyngeal swabs [32]. A case study with a pneumonia patient in Thailand showed a negative test with nasal or oropharyngeal swab samples but a positive test with bronchoalveolar lavage fluid [33]. Sampling both nasal and oropharynx is recommended to minimize the chances of virus detection error [27]. The sensitivity of nasal, nasopharyngeal (NP), and throat swabs was found to be $80 \%$, $90 \%$, and $87 \%$, respectively [34]. The difference in the sensitivity of different types of swabs may depend on disease progression. Therefore, it is important to identify the appropriate type of sample considering the medical condition of the patient and diagnostic facility available for the test. However, further comparisons on the appropriate type of sample needed may be warranted $[26,35,36]$.

\section{RT-PCR tests for virus}

The molecular detection methods involve the analysis of nucleic acids present in the sample to identify the virus. The most commonly used laboratory detection method for the clinical diagnosis of COVID-19 is real-time reverse transcriptase polymerase chain reaction (RT-PCR). The same technique has been used in the diagnosis and surveillance of various other viral diseases including SARS-CoV and MERS-CoV [8, 37, 38]. There are a number of commercially available primers and probes used in RT-PCR for the detection of SARSCoV-2 (see Table 2). Fundamentals of molecular processes 


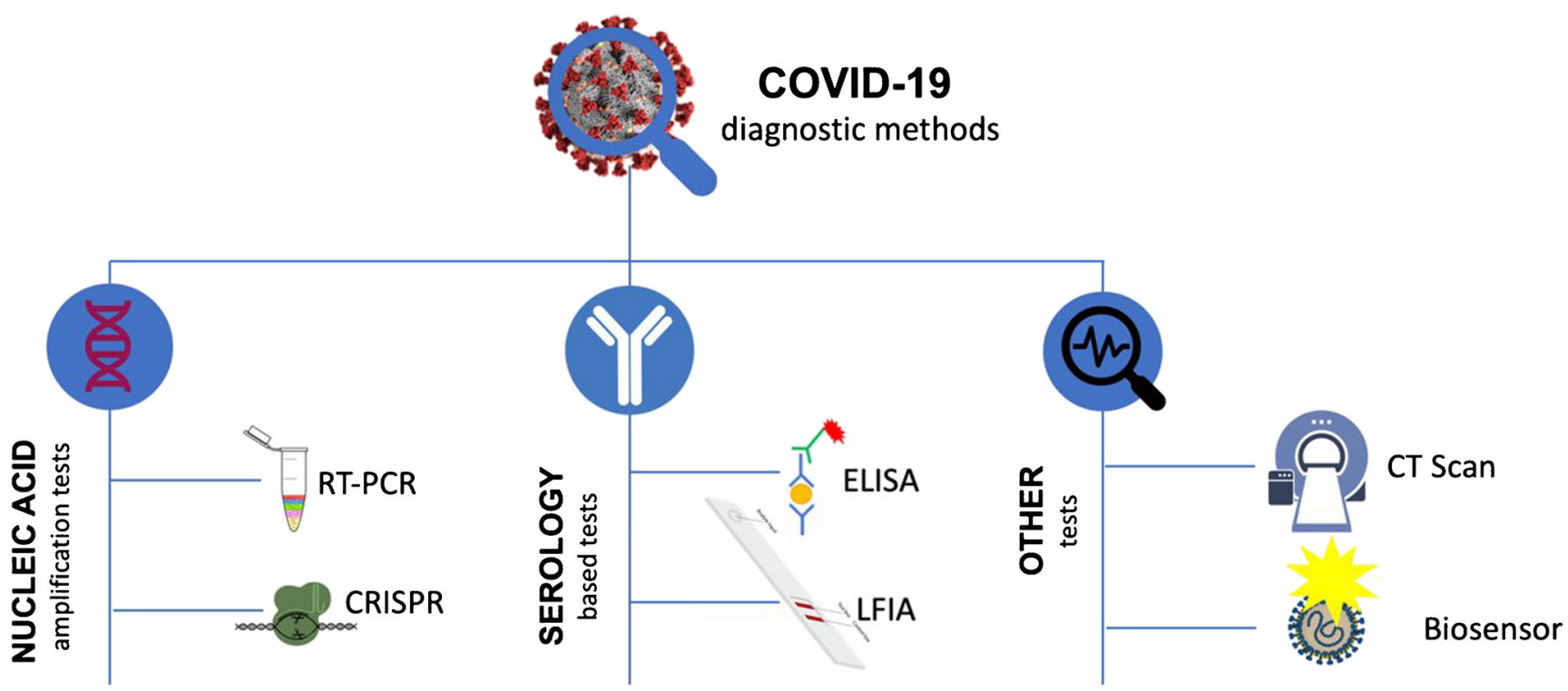

Fig. 1 Major diagnostic methods reported for the detection of SARS-CoV-2

for diagnosis of COVID-19 have been covered in a recent review article, and we refer readers to it for more basic information [25].

The RT-PCR tests take less than an hour to a couple of days to give results, depending on the version of the PCR. The RTPCR assay can be carried out in one- or two-step approaches. One-step approach is faster in which both RT and DNA polymerase are combined together to carry out their respective reaction in the same reaction tube and is a preferred approach for the detection of SARS-CoV-2 [13]. The two-step approach involves RT of RNA in one tube and subsequent DNA polymerization in a separate reaction tube. Depending on the type of assay format, a single RT-PCR machine can test one to hundreds of samples at one time.

The RT-PCR test result relies on sample collection, primers and probes used, analysis of fluorescence curves, use of suitable controls, and reliability of the temperature control. A negative control is used to check sample cross-contamination, and the positive control is used to assess the chemical integrity of the reagents, primers, and probes. In addition to these controls, the US CDC recommends the use of a human specimen control (HSC) [40] to ensure successful lysis and integrity of extraction reagents and to minimize false negative results by ensuring collection of enough human cellular material [3].

Respiratory specimens may contain different genera of coronaviruses along with other major viral pathogens. In the last six decades, before SARS-CoV-2, the human population was already infected with six other members $(229 \mathrm{E}, \mathrm{OC} 43$, SARS-CoV, NL63, HKU1, and MERS-CoV) of the CoV family [41]. False positive results occurring due to the crossreactivity with these viruses, human genome, and microflora can be obliterated with the sequence fidelity. In silico analysis using the many sequences available on publicly available databases (e.g., GenBank, the European Molecular Biology Laboratory (EMBL), Global Initiative on Sharing All Influenza Data (GISAID) to discriminate the SARS-COV-2 from other respiratory viruses is a hallmark widely employed to generate a specific primer for COVID-19 detection.

\section{Laboratory RT-PCR tests}

The RT-PCR assays in centralized laboratories are generally performed in 96-well plates for signal reading in batches. The high-throughput 384-well assay system using lower volume was reported recently with detection sensitivity down to 5 copies of viral genome per microliter [42]. The highthroughput method yielded $100 \%$ sensitivity and specificity.

The US CDC real-time RT-PCR diagnostic panel under EUA targets two different loci of the $\mathrm{N}$ gene [40]. The FDA has already issued several other molecular in vitro diagnostics under EUA [43]. In many protocols, RT-PCR assay of more than one gene target is performed for the positive authenticity of COVID-19. The US CDC considers positive results only when both gene targets ( $\mathrm{N} 1$ and $\mathrm{N} 2$ ) are positive [40]. If any of the two assays are negative, the result is inconclusive, and the assay has to be repeated following strict guidelines. Positive confirmation with a single gene target is possible if the amplicons are subjected to deep sequence analysis. The protocol from Pasteur Institute [39] utilizes IP2 and IP4 gene targets as the first-line screening tool, while confirmatory testing utilizes the $\mathrm{E}$ gene target. The Charité protocol uses the $\mathrm{E}$ gene as the screening assay followed by confirmatory assay with the RdRp gene [39]. The Chu et al. protocol recommends the $\mathrm{N}$ gene for screening, while ORF1b provides a confirmatory test [44]. A candidate assay targeting RNA sequences coding for the viral $\mathrm{E}$ and $\mathrm{N}$ proteins and RNA-dependent 


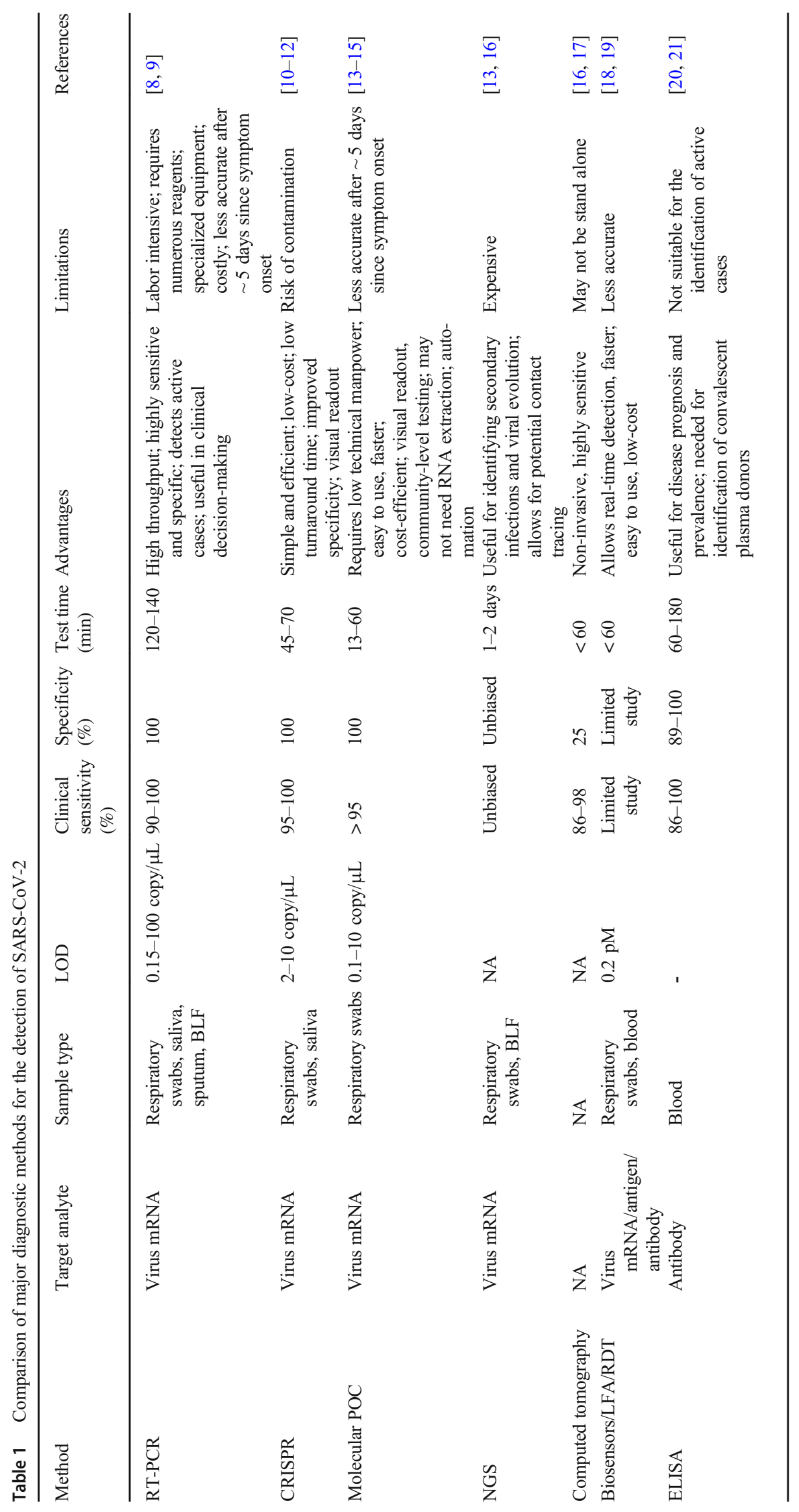


Table 2 List of primers and probes for SARS-CoV-2 [39]

\begin{tabular}{|c|c|c|c|}
\hline Gene target & Primer/probe & Sequence $\left(5^{\prime}-3^{\prime}\right)$ & Developed by \\
\hline \multirow[t]{3}{*}{ RdRp } & nCoV_IP2 Fw & ATGAGCTTAGTCCTGTTG & \multirow[t]{6}{*}{ Institut Pasteur } \\
\hline & nCoV_IP2 Rv & CTCCCTTTGTTGTGTTGT & \\
\hline & IP2 probe & HEX AGATGTCTTGTGCTGCCGGTA $^{\text {BHQ1 }}$ & \\
\hline \multirow[t]{3}{*}{$\mathrm{RdRp}$} & nCoV-IP4 Fw & GGTAACTGGTATGATTTCG & \\
\hline & nCoV_IP4 Rv & CTGGTCAAGGTTAATATAGG & \\
\hline & IP4 probe & ${ }^{\mathrm{FAM}}$ TCATACAAACCACGCCAGG ${ }^{\mathrm{BHQ} 1}$ & \\
\hline \multirow[t]{3}{*}{ ORF1b } & ORF1b-nsp14 F & TGGGGYTTTACRGGTAACCT & \multirow[t]{6}{*}{ Hong Kong University } \\
\hline & ORF 1b-nsp14 R & AACRCGCTTAACAAAGCACTC & \\
\hline & ORF1b probe & ${ }^{\text {FAM }}$ TAGTTGTGATGCWATCATGACTAG ${ }^{\text {TAMRA }}$ & \\
\hline \multirow[t]{3}{*}{$\mathrm{N}$} & HKU-NF & TAATCAGACAAGGAACTGATTA & \\
\hline & HKU-NR & CGAAGGTGTGACTTCCATG & \\
\hline & HKU probe & ${ }^{\text {FAM }}$ GCAAATTGTGCAATTTGCGG ${ }^{\text {TAMRA }}$ & \\
\hline \multirow[t]{3}{*}{ ORF1ab } & ORF1ab-F & CCCTGTGGGTTTTACACTTAA & \multirow[t]{6}{*}{ Chinese CDC } \\
\hline & ORF1ab-R & ACGATTGTGCATCAGCTGA & \\
\hline & ORF 1 ab probe & ${ }^{\text {FAM }}{ }_{\text {CCGTCTGCGGTATGTGGAAAGGTTGG }}^{\text {BHQ1 }}$ & \\
\hline \multirow[t]{3}{*}{$\mathrm{N}$} & $\mathrm{N}-\mathrm{F}$ & GGGGAACTTCTCCTGCTAGAAT & \\
\hline & N-R & CAGACATTTTGCTCTCAAGCTG & \\
\hline & $\mathrm{N}$ probe & 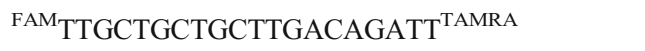 & \\
\hline \multirow[t]{3}{*}{$\mathrm{N}$} & CDC_N1-F & GACCCCAAAATCAGCGAAT & \multirow[t]{6}{*}{ US CDC } \\
\hline & CDC_N1-R & TCTGGTACTGCAGTTGAATCTG & \\
\hline & N1 probe & ${ }^{\text {FAM }}{ }^{A C C C C G C A T T A C G T T T G G T G G A C C ~}{ }^{\mathrm{BHQ} 1}$ & \\
\hline \multirow[t]{3}{*}{$\mathrm{N}$} & CDC_N2_F & TTACAAACATTGGCCGCAAA & \\
\hline & CDC_N2-R & GCGCGACATTCCGAAGAA & \\
\hline & $\mathrm{N} 2$ probe & ${ }^{\text {FAM }}{ }_{\text {ACAATTTGCCCCCAGCGCTTCAG }}^{\text {BHQ1 }}$ & \\
\hline \multirow[t]{4}{*}{$\mathrm{RdRp}$} & RdRp_F2 & GTGARATGGTCATGTGTGGCGG & \multirow[t]{7}{*}{ Charité } \\
\hline & RdRp_R1 & CARATGTTAAASACACTATTAGCATA & \\
\hline & RdRp-P2 probe & ${ }^{{ }^{\text {FAM }} \text { CAGGTGGAACCTCATCAGGAGATGC }}{ }^{\text {BBQ }}$ & \\
\hline & RdRp-P1 probe & ${ }^{\text {FAM }}{ }^{C C A G G T G G W A C R T C A T C M G G T G A T G C ~}{ }^{\mathrm{BBQ}}$ & \\
\hline \multirow[t]{3}{*}{$\mathrm{E}$} & E_Sarbeco_F1 & ACAGGTACGTTAATAGTTAATAGCGT & \\
\hline & E_Sarbeco_R2 & ATATTGCAGCAGTACGCACACA & \\
\hline & E_Probe & FAM ACACTAGCCATCCTTACTGCGCTTCG ${ }^{\text {BHQ1 }}$ & \\
\hline \multirow[t]{3}{*}{$\mathrm{N}$} & WH-NIC N-F & CGTTTGGTGGACCCTCAGAT & \multirow[t]{3}{*}{ MPH, Thailand } \\
\hline & WH-NIC N-R & CCCCACTGCGTTCTCCATT & \\
\hline & WH-N probe & ${ }^{\text {FAM }}$ CAACTGGCAGTAACCA ${ }^{\text {BHQ1 }}$ & \\
\hline \multirow[t]{3}{*}{$\mathrm{N}$} & NIID_N_F2 & AAATTTTGGGGACCAGGAAC & \multirow[t]{3}{*}{ NIID, Japan } \\
\hline & NIID_N_R2 & TGGCAGCTGTGTAGGTCAAC & \\
\hline & NIID $\mathrm{N}$ probe & FAM ATGTCGCGCATTGGCATGGA $^{\text {BHQ }}$ & \\
\hline
\end{tabular}

MPH Ministry of Public Health, NIID National Institute of Infectious Diseases

RNA polymerase ( $R d R p)$ showed good alignment of the selected primers and probes with the SARS-CoV-2 genome [8].

Primer sets (IP2 and IP4) designed by Pasteur Institute, when used individually in an assay, can detect about 100 copies of RNA genome equivalent per reaction at $95 \%$ detection probability. A lower LOD of 10 copies was obtained with a multiplex assay using these primer sets [39]. Chu et al. used the cloned DNA plasmid containing SARS-CoV ORF1b and $\mathrm{N}$ gene to calculate the LOD of their assay. With a known titer of viral RNA, their preliminary study showed the LOD of $<10$ copies per reaction [44]. A dynamic range of seven orders of magnitude $\left(2 \times 10^{-4}\right.$ to $2 \times 10^{3} \mathrm{TCID}_{50} /$ reaction $)$ was obtained using RNA extracted from cells infected by SARS coronavirus as a positive control using one-step RT-PCR assays to detect two different regions (ORF1b and $\mathrm{N}$ ) of the viral genome [44].

Further improvement in the sensitivity was found in the Charite protocol [8]. They conducted a proficiency testing for the sensitivity with E Sarbeco and RdRp genes using in vitro transcribed RNA derived from SARS-CoV strain Frankfurt-1, where they found LOD of 5.2 and 3.8 copies per reaction, respectively, which was in good agreement with other participating laboratories. They also found the $\mathrm{N}$ gene assay was slightly less sensitive than the RdRp and the E 
Sarbeco gene. The US CDC diagnostic panel showed the LOD of 1 copy of RNA per microliter for both N1 and N2 primer sets [40]. However, sensitivity was affected by the use of different RNA extraction and purification protocols. A comparative study [9] on the analytical sensitivity of four commonly used assays approved by the WHO found the nCoV-N2 primer set from the US CDC was prone to background amplification, which impairs the ability to distinguish between true positive and negative results at low virus concentration. The same study showed primer/probe sets E Sarbeco from the Charite protocol and ORF1b-nsp14 from the Hong Kong University (HKU) protocol were the most sensitive with an LOD of 10 virus genome equivalents per microliter at $75 \%$ detection frequency [9].

The PCR assays developed by Pasteur Institute have been claimed to not cross-react with respiratory viruses like influenza A (H1N1, H3N2), enterovirus, adenovirus, human coronaviruses (HKU1, OC43, 22E, NL63), and MERS$\mathrm{CoV}$, indicating $100 \%$ specificity. Assays from HKU are specific to only subgenus Sarbecoviruses [44]. This assay did not distinguish between SARS-CoV and SARS-CoV-2 transcripts because SARS-CoV-2 shares a 79.6\% sequence identity with SARS-CoV BJ01 [5], and many of the regions homologous with the primers are conserved nucleotide regions [4]. In contrast, another comparative study showed that the N2 primer/probe set developed by US CDC was highly sensitive comparable with the E Sarbeco set described in Charité assay at low viral copy number [45]. A PCR assay with absolute exclusiveness to SARS-CoV-2 was made possible in the Charite protocol with the inclusion of additional probe (RdRp_P2) (see Table 2) that anneals to only SARS-CoV-2 mRNA transcript. Nonetheless, this protocol does not discriminate between clades of the Sarbecoviruses like SARS-related CoVs from bats. This overlap is corroborated with the sim plot of SARS-CoV-2 showing more than $96 \%$ identity to a bat coronavirus [5]. Primers based on the receptor binding domain of the $\mathrm{S}$ gene developed by Zhou et al. could discriminate SARS-CoV-2 from bat SARSr-CoV WIV1 [5]. Assays (N1 and N2) based on the US CDC-developed method could also provide specific detection against SARS-CoV-2 [46]. Diagnostic sensitivity and specificity of various methods are given in Table 3.

Multiple studies have shown that the clinical sensitivity of a RT-PCR assay is under the influence of specimen type, amount of virus in a swab and the specimen collection time in relation to the onset of symptoms. In one study with 205 patients, RT-PCR sensitivity was $93 \%$ for BLF, $72 \%$ for sputum, $63 \%$ for nasal swabs, and only $32 \%$ for throat swabs [23]. The presence of viral load that is below the assay's LOD will also elicit false negative results. Therefore, a judicious way to increase viral load is to collect combined nose and throat swabs. Viral kinetics of SARS-CoV-2 showed that the viral load in respiratory specimens often peaks in the first week of illness and decreases as the disease progresses [54]. This posited appropriate sample collection times to enhance sensitivity. These findings are similar to a report that showed a $100 \%$ positive RT-PCR result by week 1 after onset of symptoms, followed by $89.3 \%, 66 \%$, and $32 \%$ at week 2 , week 3 , and week4, respectively. By week 5 , the positive detection rate plummeted down to only $5.4 \%$ [55]. In contrast to the widely used NP swabs, a study more recently showed an increase in the sensitivity by $13 \%$ when saliva samples were used [56]. Virus titers from saliva samples were found significantly higher than NP swabs and more importantly, unlike NP swabs, less temporal variation in viral titer was observed with longitudinally collected saliva samples. To accurately estimate diagnostic sensitivity, a clear-cut generalization regarding specimen quality through a rigorous study with large sample size on the dynamic of viral shedding and its correlation across the time course of infection is required.

\section{POC tests for SARS-CoV-2 genes}

The point-of-care (POC) methods are less complex to perform, give results within several minutes, and can be performed on site. They may provide alternative diagnostic methods more suitable for widespread population testing.

A preliminary study reported a POC system capable of detecting genes coding for the N protein of SARS-CoV-2 in respiratory samples [14]. Molecular POC tests utilize RT-PCR or loop-mediated isothermal amplification (LAMP) or other isothermal nucleic acid amplification methodologies [57]. These devices process 1-2 samples at a time. Some of the sample-processing steps can be automated to reduce the test time to under $1 \mathrm{~h}$. While public information on these systems is still limited, the LOD of one such device is reported to be in the range of 120-200 genome equivalents/mL [57].

In an effort to enhance the sensitivity of the LAMP method, a two-stage isothermal amplification (COVID-19 PennRAMP) method has been described, producing 10 to 100 fold better sensitivity than conventional LAMP and RT-PCR tests. This test is carried out in a closed tube and employs fluorescence or colorimetric detection. This POC method has been proposed as a rapid, highly sensitive molecular test amenable for use at home, in the clinic and at point of entry by minimally trained individuals and with minimal instrumentation. This method as reported, however, was not yet tested in patient samples [58].

Two of the first POC platforms receiving EUA from FDA are produced by Abbott and Cepheid. The Abbott ID NOW COVID-19 system gives positive results in $5 \mathrm{~min}$ and negative results in 13 min after sample preparation. The Xpert $®$ Xpress SARS-CoV-2 system can give results in $\sim 30$ min with less than a minute sample preparation. It is interesting to note that the Abbott technology missed one-third of samples detected positive by Cepheid Xpert Xpress [59]. 


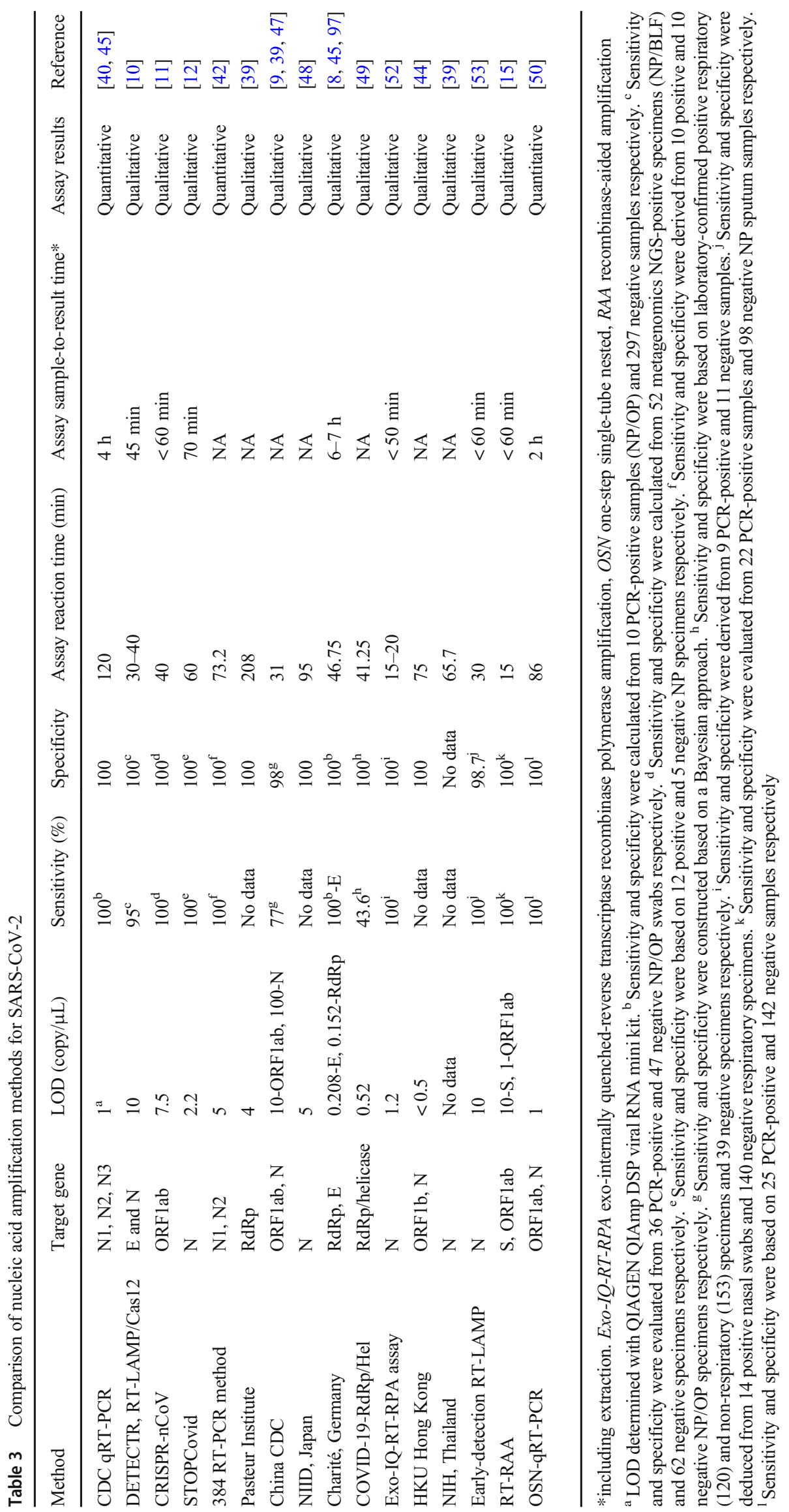


The ePlex ${ }^{\circledR}$ SARS-CoV-2 is a qualitative automated nucleic acid multiplex platform and sample-to-answer system capable of automating extraction, amplification, and detection in a single-use cartridge. A simple visual readout similar to a pregnancy test has been described. This POC system is based on SHERLOCK technology and has been called STOPCovid (SHERLOCK Testing in One Pot) [12]. It uses AapCas12b protein coupled with guided RNA that contains spacer sequence for the specific detection of SARS-CoV-2 N gene. It was anticipated that this technique could be deployed at home using saliva samples and cheaply available cookers for LAMP. Some of these EUA technologies may need more rigorous testing to make sure of their reliability and sensitivity.

\section{Limitations of RT-PCR methods}

While having the advantage of accommodating large batches of samples, the conventional RT-PCR test and the facility it requires, including the PCR machines, are too expensive. When transport to a competent laboratory is included, the turnaround time is measured in days. Additionally, sample preparation and assay procedures require well-trained manpower. These shortcomings limit the wider use of the technology during viral pandemics. In addition, high demand during the pandemic creates a shortage of swabs, personal protective equipment, PCR reagents, and equipment such as thermocyclers and biosafety level-2 cabinets, further delaying the diagnosis. Since RT-PCR assays amplify specific target loci, the assays will report a negative result if the particular target locus is not present in the sample. Collective genetic data indicate changes in the viral genome due to insertion or deletion, recombination, and interchange are frequent among CoVs $[60,61]$. If this is the case, even a single-nucleotide polymorphism due to mutation at the primer or probe binding site could vitiate the true RT-PCR result. The sensitivity may not be enough to detect early infections due to low concentrations of the virus, especially in asymptomatic cases and may result in false negative results. During the COVID-19 pandemic, there is a growing concern about the inaccessibility of RNA-based testing methods and a global shortage of reagents [62].

\section{Emerging techniques}

Apart from conventional RT-PCR, additional molecular diagnostic tools are emerging for SARS-CoV-2. Whole-genome sequencing of SARS-CoV-2 has the potential to overcome the limitations of RT-PCR. Genomic sequencing can detect fragments even when a complete genome is not present in the sample. Notably, the SARS-CoV-2 genome is free of repeats, making it susceptible to complete characterization using short sequence reads. The genome sequencing involves the construction of RNA library, next-generation sequencing (NGS) of the RNA construct, de novo assembly of the qualitytrimmed reads to generate a contig map, and phylogenetic analysis [63]. The genome sequencing may overcome the false results arising from specious priming. However, due to cost, technical complexities associated with the instrument, data analysis, and higher turnaround time of 24 to $48 \mathrm{~h}$, this method may not be a routine use for clinical diagnosis during pandemic [64]. A novel method based on the Sanger sequencing was developed by the Chandler-Brown group that targets the SARS-CoV-2 N protein [65]. This method uses COVID19 spike-in DNA as an internal control that provides quantification of the viral mRNA. The major advantages of this method are the omission of RNA extraction procedure so there will be no impedance in the testing capacity due to shortage of RNA extraction kits and potential for a very high throughput of one million tests per day with proper customization of the sequencer.

Another emerging method is CRISPR-based technologies. A rapid (<40 min), easy-to-implement, and accurate CRISPR-Cas12-based lateral flow assay for the detection of SARS-CoV-2 from respiratory swab RNA extracts has been recently reported. The CRISPR-based DETECTR (DNA Endonuclease-Targeted CRISPR Trans Reporter) has a visual read for results. This assay performed simultaneous RT and LAMP steps, followed by Cas 12 detection of predefined coronavirus sequences, after which cleavage of a reporter molecule confirms detection of the virus. The LOD of this method was 10 copies per microliter reaction. Clinical sensitivity and specificity were $95 \%$ and $100 \%$, respectively, for the detection of the coronavirus in 83 total respiratory swab samples [10]. Another CRISPR-based detection system called SHERLOCK (Specific High Sensitivity Enzyme Reporter UnLOCKing) that targets $\mathrm{S}$ and ORF1ab gene fragments of SARS-CoV-2 was described by Sherlock Biosciences. This method was able to detect synthetic COVID-19 RNA sequence in a range between 10 and 100 copies per microliter and could be completed within $1 \mathrm{~h}$ [66]. A new platform with engineered complementary recombinant RNA (crRNA) has been reported with LOD as low as $~ 700 \mathrm{fM}$ cDNA from HIV, $290 \mathrm{fM}$ RNA from $\mathrm{HCV}$, and $370 \mathrm{fM}$ cDNA from SARS-CoV-2 in $30 \mathrm{~min}$ without a need for target amplification. In this case, the isothermal amplification of SARS-CoV-2 RNA was performed using RT-LAMP, and the modified crRNAs were incorporated in a paper-based lateral flow assay that could detect the target within 40-60 $\mathrm{min}$ [67].

Droplet-based digital PCR (dPCR) methods have also been sought as a more sensitive method to test for the RNA of SARS-CoV-2. This method, when tested in 77 patient samples, showed an improved sensitivity from 44 to $94 \%$ and the same specificity when compared with the RT-PCR method [68]. The LOD of the same method has been reported to be 2.1 copies/reaction for ORF1ab and 1.8 copies/reaction for $\mathrm{N}$ primer/probe set. In a similar dPCR method, the LOD was 2 
copies/reaction [69]. When tested in 103 fever-suspected patients, the dPCR method improved the sensitivity from $28.2 \%$ with RT-PCR to $87.4 \%$ with dPCR.

A dual-functional plasmonic biosensor that combined the plasmonic photothermal effect and localized surface plasmon resonance sensing transduction was reported as an alternative for the clinical diagnosis of COVID-19 [18]. Twodimensional gold nano-islands functionalized with complementary DNA receptors were used to detect SARS-CoV-2 through nucleic acid hybridization. The biosensor was able to detect $0.22 \mathrm{pM}$ and allowed precise detection of the specific target in a multigene mixture. Gold nanoparticles (AuNPs) functionalized with antisense oligonucleotides were developed for the simultaneous detection of two regions of the SARS-CoV-2 N gene [70]. In the presence of RNA target, AuNPs agglomerate, and the agglomeration is further enhanced by the addition of RNAse $\mathrm{H}$ enzyme to generate a distinguishable visible precipitate. An electrochemical ultrasensitive POC device named eCovSens detects the spike protein of SARS-CoV-2 within 10 to $30 \mathrm{~s}$ [71]. This device was fabricated by immobilizing antibody against $\mathrm{S} 1$ protein on screen-printed carbon electrodes. With spiked saliva samples, the LOD of the device was found to be $90 \mathrm{fM}$.

Though relatively slow and expensive, computed tomography (CT) of the chest has also been explored in the diagnosis of COVID-19 as a complementary tool to molecular techniques when combined with medical history and clinical observations [65]. In a recent study, artificial intelligence artificial intelligence (AI) algorithms were used to integrate chest CT findings with clinical symptoms, exposure history, and laboratory testing to rapidly diagnose patients who are positive for COVID-19 [51]. The AI system had equal sensitivity as compared with a senior thoracic radiologist. In addition, it improved the detection of patients who were positive for COVID-19 via RT-PCR who presented with normal CT scans, correctly identifying 17 of $25(68 \%)$ patients, whereas radiologists classified all of these patients as negative for COVID-19. When CT scans and associated clinical history are available, the proposed AI system can help to diagnose COVID-19 patients. The supplementary CT scan imaging may help to rule out negative RT-PCR results [16].

\section{Immunoassays for antibody to virus}

Immunoassays are one of the widely used bioanalytical methods to detect and/or quantify an analyte using an antigen-antibody interaction. While there are a few reports using antibodies in a biosensor to detect virus directly [19], the affinity of most antibodies is not sufficient for direct detection of small numbers of virus particles. Most immunoassays used for testing individuals for COVID-19 exposure detect specific antibodies (IgG and $\operatorname{IgM}$ ) in the serum that react with SARS-CoV-2 proteins. IgM is expressed earlier during an infection ( $\sim 3-6$ days) and IgG is the late antibody detectable only after $\sim 8$ days. IgG is generally more specific for a protein antigen than IgM and affinity generally increases with continued exposure to the (viral) antigen [72].

Enzyme-linked immunosorbent assays (ELISAs) and lateral flow immunoassays (LFIAs) are the most widely practiced techniques to detect the antibodies against SARS-CoV-2 [73]. A two-stage ELISA protocol was described for measuring human antibody responses to the recombinant receptor-binding domain (RBD) of the spike protein or full-length spike protein of SARS-CoV-2 by Krammer's group from the Icahn School of Medicine in New York [74]. The first stage included a highthroughput screening of samples in a single-serum dilution against the RBD, followed by a second stage in which positive samples from the first stage underwent a confirmatory ELISA against the full-length spike protein.

Recently, a peptide-based magnetic chemiluminescence enzyme immunoassay was developed for the diagnosis of COVID-19 [75]. The test has high throughput and can perform simultaneous clinical tests for other biomarkers, such as C-reactive protein (CRP), which should also be tracked in COVID-19 suspects [76].

The sensitivity of the immunoassays for the presence of antibodies in human samples may depend on the viral titer and time of sample collected after viral infection; both factors impact circulating antibody concentration [77]. ELISA and chemiluminescence assays based on the antibodies have shown a sensitivity of $70-95 \%$ and $82-97 \%$ respectively [78-80]. A peptide luminescence method was developed with recombinant $\mathrm{S}$ protein to detect IgM and IgG antibody. The total positive rate of detection was $81 \%$ with $<6 \%$ coefficient of variation.

The immunoassay-based rapid diagnostic test (RDT) kits, depending on the vendor type, are reported to have sensitivity in the range of $60-80 \%$ and selectivity of $85-100 \%$ at a confidence interval of 95\% [57]. The RDTs that are LFIAs have shown $86 \%$ to $88 \%$ sensitivity and $90 \%$ to $99 \%$ specificity to detect total antibodies $[78,79,81,82]$. A study by Bendavid et al. demonstrated $82 \%$ sensitivity and $99.5 \%$ specificity for detecting antibodies to SARS-CoV-2 tested in 3330 adults and children in Santa Clara County, CA, using LFIAs [29]. A test that detects both IgM and IgG produced a sensitivity, specificity, and accuracy of $57 \%, 100 \%$, and $69 \%$ for IgM and $81 \%, 100 \%$, and $86 \%$ for IgG, respectively. Combining the results from both $\operatorname{IgM}$ and $\operatorname{IgG}$ yielded a clinical sensitivity of $82 \%$ [83]. Analytical performance of various immunoassay methods for COVID-19 detection has been summarized in Table 4 . A rapid $(10 \mathrm{~min})$ and sensitive LFIA that uses lanthanide-doped polystyrene nanoparticles to detect anti-SARS-CoV-2 IgG has also been reported [84]. 
Table 4 Comparison of analytical performances of immunoassay-based COVID-19 diagnostic methods

\begin{tabular}{|c|c|c|c|c|c|}
\hline Manufacturer & Method & Clinical sensitivity (\%) & Specificity $(\%)$ & Assay time (min) & References \\
\hline Premier Biotech, Minneapolis, MN & LFIA & 80.3 & 99.5 & $12-20$ & [28] \\
\hline Zhu Hai Liv Zon Diagnostics Inc., China & LFIA & 82.4 & 100 & $10-15$ & [79] \\
\hline AutoBio Diagnostics, Zhengzhou, China & LFIA & 93 & 100 & $15-20$ & {$[21]$} \\
\hline Artron Laboratories & LFIA & 83 & 100 & $15-20$ & [21] \\
\hline Shanghai KinBio Inc. & LFIA & 88.7 & 90.6 & 15 & {$[78]$} \\
\hline Epitope diagnostics (EDI), USA & ELISA & 100 & 88.7 & 80 & {$[20]$} \\
\hline Euroimmun, Germany & ELISA & 86.4 & 96.2 & $60-120$ & {$[20]$} \\
\hline Zhu Hai Liv Zon Diagnostics Inc., China & ELISA & 87.3 & 100 & 180 & [79] \\
\hline Mikrogen, Germany & ELISA & 86.4 & 100 & $120-180$ & {$[20]$} \\
\hline Shenzhen YHLO Biotech Co., Ltd. & Chemiluminescence & 88.9 & 90 & 30 & {$[82]$} \\
\hline Kangrun Biotech, Guangzhou, China & Chemiluminescence & 96.8 & 99.8 & $30-35$ & {$[83]$} \\
\hline
\end{tabular}

The Single Molecule Array (SIMOA) multiplexed method developed by Quanterix targets three immunoglobulin responses (IgG, IgM, and IgA) to four viral proteins (spike protein, S1 subunit, receptor binding domain, and nucleocapsid) in a single sample, thereby enabling the quantification of 12 antibody isotype-viral protein interactions. It gives a highresolution profile of immune response of SARS-CoV-19 when compared with a traditional ELISA where only a single interaction can be interrogated. The SIMOA method demonstrated a sensitivity of $86 \%$ and a specificity of $100 \%$ during the first week of infection, and $100 \%$ sensitivity and specificity thereafter [85].

RDTs employing serological immunoassays are less complex, cost less than the molecular tests, and can give results in a short time period. Immunoassays are good tools to track and study past infections, especially in asymptomatic cases. Serological assays can be used to determine the infection rate and to estimate the population extent and prevalence of infection. Results from a serological survey can also be used to project mortality rates in a community. Furthermore, they are useful to characterize the immune response to the virus. A serological assay is critical for identifying potential plasma donors and for developing vaccines. These tests are relatively quick, are easy to use, and require no highly trained personnel and sophisticated equipment. By early August 2020, a quick scan of the internet showed over 20 rapid tests under commercialization with the European CE Mark approval.

\section{Limitations of immunoassay methods}

Immunoassays are not as specific as the tests recognizing RNA sequences in the virus. In the past, molecules like interferon, rheumatoid factor, and non-specific IgM have been shown to cause problems in immunoassays [80], and levels of such potential interferents can be highly variable in COVID-19 patients.
Immunoassays to detect the antibody response to virus may produce false negative results during the early stage of the infection. The sensitivity may be low when tested in local populations with asymptomatic or mildly symptomatic individuals who may generate only low-titer antibodies. Sensitivity may be even lower if there are many such cases. Results may also be biased due to prior COVID-like illnesses that confound the specificity of the antibody response. One of the difficulties in validating an assay for antiviral antibodies is the availability of appropriate negative and positive controls. Negative controls are easier to come by and can be serum pools taken before 2019. Positive controls can be convalescent samples from COVID-19 patients or monoclonal antibodies like CR3022 [29]. Despite high sensitivity, the antigen used in an assay might not be an ideal protein of choice to target for diagnostics because the protein is highly conserved across a broad spectrum of coronavirus in many animals, e.g., the $\mathrm{N}$ protein of SARS-CoV from feline infectious peritonitis virus and porcine transmissible gastroenteritis virus [78]. In some instances, $\mathrm{N}$ protein-based immunoassays were unable to differentiate SARS patients from healthy individuals. So, the serum diagnostics are complex, requiring more than just one antigenic protein to be used as a target [86].

To add to the complexity of interpreting results from diagnostics for antiviral antibodies, the antibody response in a patient depends on age, nutritional status, and existing medical conditions and medications [54, 87]. The majority of patients develop antibodies only after the second week of infection, i.e., in the recovery phase of COVID $[88,89]$. By this phase, many of the opportunities for disease intervention are already passed. Antibody tests may also cross-react with other pathogens and human coronavirus and give false positive results $[54,90]$. Serological tests may be useful for epidemiology, but not sufficiently reliable for clinical diagnosis [91].

It has been suggested to detect multiple antibodies to avoid false results. Antisera raised against $\mathrm{N}$ proteins lack specificity 
and need to be used in combination with antibodies to other proteins; e.g., antisera against $\mathrm{N}$ proteins and $\mathrm{S}$ proteins might be used to develop a more reliable serum-based quick diagnostic test kits [80,92,93]. To improve the sensitivity, it is paramount to include other biomarkers of the early stage of SARS-CoV-2 infection [76]. The WHO has not recommended the use of antibody-based POC systems in clinical decision-making [18].

\section{Future perspectives}

Among various methods available for the detection of COVID-19, the RT-PCR is the most reliable and widely used method. During pandemic emergencies, shortage of resources such as PCR kits is common. It is therefore important to have multiple options for the diagnostic methods. Alternative testing platforms and accessories that could be locally manufactured, even in a small scale, are equally important. Such platforms would be appropriate in resource-limited settings as well. The currently practiced RT-PCR methods are costly, and therefore many countries, especially the lowincome ones, cannot afford enough number of COVID-19 tests to screen larger population. Important gaps remain in screening asymptomatic persons in the incubation phase. Accurate determination of live viral shedding among patients in the convalescence phase to inform de-isolation decisions is also challenging.

Quality assurance and regulatory frameworks surrounding testing remain a challenge. There are several instances of COVID-19 test kits being recalled in several countries due to suspicious quality. The lack of an established reference standard, the use of differing sample collection and preparation methods, and an incomplete understanding of viral dynamics across the time course of infection hamper the rigorous assessment of the diagnostic accuracy of the many newly introduced SARS-CoV-2 assays [7].

New technologies such as CRISPR-based diagnostics and implementation of practical approaches for POC applications such as RT-LAMP will provide rapid, simple, low-cost, portable, temperature-stable assay systems that are appropriate resource-limited settings, not only for doctor's offices but also for airports, border crossings, and remote locations. One of the research areas to be explored for diagnosis of COVID-19 is to perform the serological assays in microfluidic POC systems. Microfluidic systems offer advantages of small sample volume, miniaturization, portability, multiplexed analyses, and rapid detection and can increase the sensitivity of analyte detection using signal amplification strategies [94]. The application of such a system for the diagnosis of HIV patients was previously reported with sensitivity, specificity, and test time of $92-100 \%, 79-100 \%$, and $15 \mathrm{~min}$, respectively [95]. Simple antigen-based immunoassay POC tests and molecular POC system based on paper microfluidics are also promising alternatives. A LAMP-on-paper POC system has been reported for the detection of dengue virus [95]. A conceptual framework of such a system for COVID diagnosis has already been provided by Yang et al. [96]. The integration of smartphones, which are common in most parts of the world, with the POC diagnostic system is promising to read, analyze, and report the assay results. Considering the fact that the possibility of COVID-19 infection will remain in the population like the flu viruses, a multiplex testing method for multiple diseases should be considered as a routine testing platform in future.

Authors' contribution All authors have consented to the publication of this manuscript. The manuscript is not submitted to any other journal. B. Giri and B. Neupane conceived the review, contributed to assembling the references along with R. Shrestha, S. Pandey, and K. Pokharel; all five coauthors collaborated in drafting the review. F. Ligler reorganized and edited the manuscript.

Funding Funding for RS, SP, and KP was provided by the National Academy of Sciences and USAID through partnerships for Enhanced Engagement in Research (PEER) (AID-OAA-A-11-00012). FSL is supported by the Ross M. Lampe Chair and North Carolina State University.

\section{Compliance with ethical standards}

Conflict of interest The authors declare that they have no conflict of interest.

Disclaimer The opinions, findings, conclusions, or recommendations expressed in this article are those of the authors alone and do not necessarily reflect the views of funding agencies.

Open Access This article is licensed under a Creative Commons Attribution 4.0 International License, which permits use, sharing, adaptation, distribution and reproduction in any medium or format, as long as you give appropriate credit to the original author(s) and the source, provide a link to the Creative Commons licence, and indicate if changes were made. The images or other third party material in this article are included in the article's Creative Commons licence, unless indicated otherwise in a credit line to the material. If material is not included in the article's Creative Commons licence and your intended use is not permitted by statutory regulation or exceeds the permitted use, you will need to obtain permission directly from the copyright holder. To view a copy of this licence, visit http://creativecommons.org/licenses/by/4.0/.

\section{References}

1. WHO. Coronavirus disease (COVID-19) situation reports https:// www.who.int/emergencies/diseases/novel-coronavirus-2019/ situation-reports. Accessed 28 Apr 2020.

2. Gorbalenya AE, Baker SC, Baric RS, de Groot RJ, Drosten C, Gulyaeva AA, et al. The species severe acute respiratory syndrome-related coronavirus: classifying 2019-NCoV and naming it SARS-CoV-2. Nat Microbiol. 2020;5:536-44. https://doi.org/10. 1038/s41564-020-0695-z. 
3. Wu F, Zhao S, Yu B, Chen Y-M, Wang W, Song Z-G, et al. A new coronavirus associated with human respiratory disease in China. Nature. 2020;579:265-9.

4. Lu R, Zhao X, Li J, Niu P, Yang B, Wu H, et al. Genomic characterization and epidemiology of 2019 novel coronavirus: implications for virus origins and receptor binding. Lancet. 2020;395: 565-74.

5. Zhou P, Yang X-L, Wang X-G, Hu B, Zhang L, Zhang W, et al. A pneumonia outbreak associated with a new coronavirus of probable bat origin. Nature. 2020;579:270-3.

6. Lam TT-Y, Shum MH-H, Zhu H-C, Tong Y-G, Ni X-B, Liao Y-S, et al. Identifying SARS-CoV-2 related coronaviruses in Malayan pangolins. Nature. 2020;579:1-6.

7. Cheng MP, Papenburg J, Desjardins M, Kanjilal S, Quach C, Libman M, et al. Diagnostic testing for severe acute respiratory syndrome-related coronavirus-2: a narrative review. Ann Intern Med. 2020. https://doi.org/10.7326/M20-1301.

8. Corman VM, Landt O, Kaiser M, Molenkamp R, Meijer A, Chu DK, et al. Detection of 2019 novel coronavirus [2019-NCoV] by real-time RT-PCR. Eurosurveillance. 2020;25:2000045.

9. Vogels CBF, Brito AF, Wyllie AL, et al. Analytical sensitivity and efficiency comparisons of SARS-This pre-print paper has now been published in a peer review journal. Please replace with following: CoV-2 RT-qPCR primer-probe sets. Nat Microbiol. 2020. https:// doi.org/10.1038/s41564-020-0761-6.

10. Broughton JP, Deng X, Yu G, Fasching CL, Servellita V, Singh J, et al. CRISPR-Cas12-based detection of SARS-CoV-2. Nat Biotechnol. 2020. https://doi.org/10.1038/s41587-020-0513-4.

11. Hou T, Zeng W, Yang M, Chen W, Ren L, Ai J, et al. Development and evaluation of a CRISPR-based diagnostic for 2019-novel coronavirus. medRxiv. 2020. https://doi.org/10.1101/2020.02.22. 20025460 .

12. Joung J, Ladha A, Saito M, Segel M, Bruneau R, Meei-li WH, et al. Point-of-care testing for COVID-19 using SHERLOCK diagnostics. medRxiv. 2020. https://doi.org/10.1101/2020.05.04.20091231

13. Carter LJ, Garner LV, Smoot JW, Li Y, Zhou Q, Saveson CJ, et al. Assay techniques and test development for COVID-19 diagnosis. ACS Cent Sci. 2020;6:591-605. https://doi.org/10.1021/acscentsci. 0c00501.

14. Green K, Graziadio S, Turner P, Fanshawe T, Allen J. Molecular and antibody point-of-care tests to support the screening, diagnosis and monitoring of COVID-19. Oxford COVID-19 Evidence Service. 2020. https://www.cebm.net/covid-19/molecular-andantibody-point-of-care-tests-to-support-the-screening-diagnosisand-monitoring-of-covid-19. Accessed 2 July 2020.

15. Xue G, Li S, Zhang W, Du B, Cui J, Yan C, et al. A reversetranscription recombinase-aided amplification assay for rapid detection of the 2019 novel coronavirus [SARS-CoV-2]. Anal Chem. 2020. https://doi.org/10.1021/acs.analchem.0c01032.

16. Ai T, Yang Z, Hou H, Zhan C, Chen C, Lv W, et al. Correlation of chest CT and RT-PCR testing in coronavirus disease 2019 [COVID-19] in China: a report of 1014 cases. Radiology. 2020;200642. https://doi.org/10.1148/radiol.2020200642.

17. Udugama B, Kadhiresan P, Kozlowski HN, Malekjahani A, Osborne M, Li VY, et al. Diagnosing COVID-19: the disease and tools for detection. ACS Nano. 2020;14:3822-35.

18. Qiu G, Gai Z, Tao Y, Schmitt J, Kullak-Ublick GA, Wang J. Dualfunctional plasmonic photothermal biosensors for highly accurate severe acute respiratory syndrome coronavirus 2 detection. ACS Nano. 2020;14:5268-77.

19. Seo G, Lee G, Kim MJ, Baek S-H, Choi M, Ku KB, et al. Rapid detection of COVID-19 causative virus [SARS-CoV-2] in human nasopharyngeal swab specimens using field-effect transistor-based biosensor. ACS Nano. 2020;14:5135-42.

20. Krüttgen A, Cornelissen CG, Dreher M, Hornef M, Imöhl M, Kleines M. Comparison of four new commercial serologic assays for determination of SARS-CoV-2 IgG. J Clin Virol. 2020:104394. https://doi.org/10.1016/j.jcv.2020.104394.

21. Lassaunière R, Frische A, Harboe ZB, Nielsen AC, Fomsgaard A, Krogfelt KA, et al. Evaluation of nine commercial SARS-CoV-2 immunoassays. Medrxiv. 2020. https://doi.org/10.1101/2020.04. 09.20056325 .

22. U.S. FDA. FAQs on emergency use authorizations [EUAs] for medical devices during the COVID-19 pandemic. FDA. 2020. https://www.fda.gov/medical-devices/emergency-situationsmedical-devices/faqs-emergency-use-authorizations-euas-medicaldevices-during-covid-19-pandemic. Accessed 2 July 2020.

23. Wang $\mathrm{W}, \mathrm{Xu} \mathrm{Y}, \mathrm{Gao} \mathrm{R}, \mathrm{Lu} \mathrm{R}, \mathrm{Han} \mathrm{K}, \mathrm{Wu} \mathrm{G}$, et al. Detection of SARS-CoV-2 in different types of clinical specimens. JAMA. 2020;323:1843-4

24. Ahmed W, Angel N, Edson J, Bibby K, Bivins A, O’Brien JW, et al. First confirmed detection of SARS-CoV-2 in untreated wastewater in Australia: a proof of concept for the wastewater surveillance of COVID-19 in the community. Sci Total Environ. 2020;138764. https://doi.org/10.1016/j.scitotenv.2020.138764.

25. Feng W, Newbigging A, Le C, Pang B, Peng H, Cao Y, et al. Molecular diagnosis of COVID-19: challenges and research needs. Anal Chem. 2020;92:10196-209.

26. See A, Toh ST. Respiratory sampling for severe acute respiratory syndrome coronavirus 2: an overview. Head Neck. 2020;42:16521656. https://doi.org/10.1002/hed.26232.

27. PHLN. PHLN Guidance on laboratory testing for SARS-CoV-2 [the virus that causes COVID-19]. PHLN. 2020. https://www. health.gov.au/sites/default/files/documents/2020/02/phlnguidance-on-laboratory-testing-for-sars-cov-2-the-virus-thatcauses-covid-19.pdf. Accessed 2 July 2020.

28. CDC. Coronavirus disease 2019 [COVID-19] https://www.cdc. gov/coronavirus/2019-ncov/lab/guidelines-clinical-specimens. html. Accessed 28 Apr 2020.

29. Bendavid E, Mulaney B, Sood N, Shah S, Ling E, BromleyDulfano R, et al. COVID-19 antibody seroprevalence in Santa Clara County, California. medRxiv. 2020. https://doi.org/10.1101/ 2020.04.14.20062463.

30. WHO. Laboratory testing for coronavirus disease 2019 [COVID19] in suspected human cases: interim guidance, 2 March 2020, World Health Organization. 2020. https://apps.who.int/iris/handle/ 10665/331329?show=full. Accessed 2 July 2020.

31. Zou L, Ruan F, Huang M, Liang L, Huang H, Hong Z, et al. SARS$\mathrm{CoV}-2$ viral load in upper respiratory specimens of infected patients. N Engl J Med. 2020;382:1177-9. https://doi.org/10.1056/ NEJMc2001737.

32. Wang X, Tan L, Wang X, Liu W, Lu Y, Cheng L, et al. Comparison of nasopharyngeal and oropharyngeal swabs for SARS-CoV-2 detection in 353 patients received tests with both specimens simultaneously. Int J Infect Dis. 2020;94:107-9.

33. Winichakoon P, Chaiwarith R, Liwsrisakun C, Salee P, Goonna A, Limsukon A, et al. Negative nasopharyngeal and oropharyngeal swabs do not rule out COVID-19. J Clin Microbiol. 2020;58(5): e00297-20.

34. Berenger BM, Fonseca K, Schneider AR, Hu J, Zelyas N. Sensitivity of nasopharyngeal, nasal and throat swab for the detection of SARS-CoV-2, preprint, Infectious Diseases [except HIV/ AIDS]. 2020. https://doi.org/10.1101/2020.05.05.20084889.

35. Irving SA, Vandermause MF, Shay DK, Belongia EA. Comparison of nasal and nasopharyngeal swabs for influenza detection in adults. Clin Med Res. 2012;10:215-8.

36. OASH. Nasal [anterior nasal] specimen collection for SARS-CoV2 diagnostic testing. https://www.cdc.gov/coronavirus/2019-ncov/ downloads/OASH-nasal-specimen-collection-fact-sheet.pdf [accessed May 20, 2020].

37. Mackay IM, Arden KE, Nitsche A. Real-time PCR in virology. Nucleic Acids Res. 2002;30:1292-305. 
38. Drosten C, Seilmaier M, Corman VM, Hartmann W, Scheible G, Sack S, et al. Clinical features and virological analysis of a case of Middle East respiratory syndrome coronavirus infection. Lancet Infect Dis. 2013;13:745-51. https://doi.org/10.1016/S14733099[13]70154-3.

39. WHO. Molecular assays to diagnose COVID-19: summary table of available protocols. World Health Organization. 2020. https:// www.who.int/publications $/ \mathrm{m} / \mathrm{item} / \mathrm{molecular}$-assays-to-diagnosecovid-19-summary-table-of-available-protocols. Accessed 2 July 2020.

40. CDC. CDC 2019-Novel coronavirus [2019-nCoV] real-time RTPCR diagnostic panel https://www.fda.gov/media/134922/ download. Accessed 2 July 2020.

41. Su S, Wong G, Shi W, Liu J, Lai AC, Zhou J, et al. Epidemiology, genetic recombination, and pathogenesis of coronaviruses. Trends Microbiol. 2016;24:490-502.

42. Nelson AC, Auch B, Schomaker M, Gohl DM, Grady P, Johnson D, et al. Analytical validation of a COVID-19 QRT-PCR detection assay using a 384-well format and three extraction methods. BioRxiv. 2020. https://doi.org/10.1101/2020.04.02.022186.

43. CDC, U. Emergency use authorizations. FDA. 2020. https://www. fda.gov/emergency-preparedness-and-response/mcm-legalregulatory-and-policy-framework/emergency-use-authorization. Accessed 2 July 2020.

44. Chu DK, Pan Y, Cheng SM, Hui KP, Krishnan P, Liu Y, et al. Molecular diagnosis of a novel coronavirus [2019-NCoV] causing an outbreak of pneumonia. Clin Chem. 2020;66:549-55.

45. Nalla AK, Casto AM, Huang M-LW, Perchetti GA, Sampoleo R, Shrestha L, et al. Comparative performance of SARS-CoV-2 detection assays using seven different primer/probe sets and one assay kit. J Clin Microbiol. 2020;58(6):e00557-20.

46. Loeffelholz MJ, Tang Y-W. Laboratory diagnosis of emerging human coronavirus infections - the state of the art. Emerg Microbes Infect. 2020;9:747-56.

47. Padhye NS. Reconstructed diagnostic sensitivity and specificity of 894 the RT-PCR test for COVID-19. medRxiv. 2020, https://doi. org/10.1101/2020.04.24.20078949

48. Shirato K, Nao N, Katano H, Takayama I, Saito S, Kato F, et al. Development of genetic diagnostic methods for novel coronavirus 2019 [NCoV-2019] in Japan. Jpn J Infect Dis. 2020. https://doi.org/ 10.7883/yoken.JJID.2020.061.

49. Chan JF-W, Yip CC-Y, To KK-W, Tang TH-C, Wong SC-Y, Leung $\mathrm{K}-\mathrm{H}$, et al. Improved molecular diagnosis of COVID-19 by the novel, highly sensitive and specific COVID-19-RdRp/Hel real-time reverse transcription-PCR assay validated in vitro and with clinical specimens. J Clin Microbiol. 2020;58:e00310-20. https://doi.org/10.1128/JCM.00310-20.

50. Wang J, Cai K, Zhang R, He X, Shen X, Liu J, et al. A novel onestep single-tube nested quantitative real-time PCR assay for highly sensitive detection of SARS-CoV-2. Anal Chem. 2020. https://doi. org/10.1021/acs.analchem.0c01884.

51. Mei X, Lee H-C, Diao K, Huang M, Lin B, Liu C, et al. Artificial intelligence-enabled rapid diagnosis of patients with COVID-19. Nat Med. 2020:1-5. https://doi.org/10. 1038/s41591-020-0931-3.

52. Behrmann O, Bachmann I, Spiegel M, Schramm M, El Wahed AA, Dobler G, et al. Rapid detection of SARS-CoV-2 by low volume real-time single tube reverse transcription recombinase polymerase amplification using an exo probe with an internally linked quencher [Exo-IQ]. Clin Chem. 2020. https://doi.org/10.1093/clinchem/ hvaa116.

53. Baek YH, Um J, Antigua KJC, Park J-H, Kim Y, Oh S, et al. Development of a reverse transcription-loop-mediated isothermal amplification as a rapid early-detection method for novel SARSCoV-2. Emerg Microbes Infect. 2020;9:998-1007.
54. Wölfel R, Corman VM, Guggemos W, Seilmaier M, Zange S, Müller MA, et al. Virological assessment of hospitalized patients with COVID-2019. Nature. 2020;581:465-9.

55. Xiao AT, Tong YX, Zhang S. Profile of RT-PCR for SARS-CoV2: a preliminary study from 56 COVID-19 patients. Clin Infect Dis. 2020. https://doi.org/10.1093/cid/ciaa460.

56. Wyllie AL, Fournier J, Casanovas-Massana A, Campbell M, Tokuyama M, Vijayakumar P, et al. Saliva is more sensitive for SARS-CoV-2 detection in COVID-19 patients than nasopharyngeal swabs. medRxiv. 2020. https://doi.org/10.1101/2020.04.16. 20067835

57. Gorse GJ, Donovan MM, Patel GB. Antibodies to coronaviruses are higher in older compared with younger adults and binding antibodies are more sensitive than neutralizing antibodies in identifying coronavirus-associated illnesses. J Med Virol. 2020;92:512-7.

58. El-Tholoth M, Bau HH, Song J. A single and two-stage, closedtube, molecular test for the 2019 novel coronavirus [COVID-19] at home, clinic, and points of entry. ChemRxiv. 2020. https://doi.org/ 10.26434/chemrxiv.11860137.v1.

59. Basu A, Zinger T, Inglima K, Woo KM, Atie O, Yurasits L, Aguero-Rosenfeld ME. Performance of Abbott ID NOW COVID-19 rapid nucleic acid amplification test in nasopharyngeal swabs transported in viral media and dry nasal swabs, in a New York City academic institution. Journal of Clinical Microbiology. 2020.

60. Cui J, Li F, Shi Z-L. Origin and evolution of pathogenic coronaviruses. Nat Rev Microbiol. 2019;17:181-92.

61. Benvenuto D, Giovanetti M, Ciccozzi A, Spoto S, Angeletti S, Ciccozzi M. The 2019-new coronavirus epidemic: evidence for virus evolution. J Med Virol. 2020;92:455-9.

62. Diao B, Wen K, Chen J, Liu Y, Yuan Z, Han C, et al. Diagnosis of acute respiratory syndrome coronavirus 2 infection by detection of nucleocapsid protein. medRxiv. 2020. https://doi.org/10.1101/ 2020.03.07.20032524

63. Chen L, Liu W, Zhang Q, Xu K, Ye G, Wu W, et al. RNA based MNGS approach identifies a novel human coronavirus from two individual pneumonia cases in 2019 Wuhan outbreak. Emerg Microbes Infect. 2020;9:313-9.

64. Ai J-W, Zhang Y, Zhang H-C, Xu T, Zhang W-H. Era of molecular diagnosis for pathogen identification of unexplained pneumonia, lessons to be learned. Emerg Microbes Infect. 2020;9:597-600.

65. Chandler-Brown D, Bueno AM, Atay O, Tsao DS. A highly scalable and rapidly deployable RNA extraction-free COVID-19 assay by quantitative sanger sequencing. bioRxiv. 2020. https://doi.org/ 10.1101/2020.04.07.029199

66. Zhang F, Abudayyeh OO, Gootenberg JS. A protocol for detection of COVID-19 using CRISPR diagnostics. 2020. https://www. broadinstitute.org/files/publications/special/COVID-19 detection (updated).pdf. Accessed 2 July 2020.

67. Nguyen LT, Smith BM, Jain PK. Enhancement of trans-cleavage activity of Cas12a with engineered CrRNA enables amplified nucleic acid detection. bioRxiv. 2020. https://doi.org/10.1101/ 2020.04.13.036079

68. Suo T, Liu X, Feng J, Guo M, Hu W, Dong G, et al. ddPCR: a more accurate tool for SARS-CoV-2 detection in low viral load specimens. Emerg Microbes Infect. 2020;9:1259-68.

69. Dong L, Zhou J, Niu C, Wang Q, Pan Y, Sheng S, et al. Highly accurate and sensitive diagnostic detection of SARS-CoV-2 by digital PCR. medRxiv. 2020. https://doi.org/10.1101/2020.03.14. 20036129

70. Moitra P, Alafeef M, Dighe K, Frieman M, Pan D. Selective nakedeye detection of SARS-CoV-2 mediated by $\mathrm{N}$ gene targeted antisense oligonucleotide capped plasmonic nanoparticles. ACS Nano. 2020;14:7617-27.

71. Mahari S, Roberts A, Shahdeo D, Gandhi S. eCovSensultrasensitive novel in-house built printed circuit board based 
electrochemical device for rapid detection of nCovid-19 antigen, a spike protein domain 1 of SARS-CoV-2. bioRxiv. 2020.

72. Janeway CA Jr, Travers P, Walport M, Shlomchik MJ. The distribution and functions of immunoglobulin isotypes. In: Immunobiology: the immune system in health and disease. 5th ed: Garland Science; 2001.

73. Li X, Geng M, Peng Y, Meng L, Lu S. Molecular immune pathogenesis and diagnosis of COVID-19. J Pharm Anal. 2020;10:1028 .

74. Stadlbauer D, Amanat F, Chromikova V, Jiang K, Strohmeier S, Arunkumar GA, et al. SARS-CoV-2 seroconversion in humans: a detailed protocol for a serological assay, antigen production, and test setup. Curr Protoc Microbiol. 2020;57:e100.

75. Cai XF, Chen J, Long QX, Deng HJ, Liu P, Fan K, Li ZJ. A Peptide-Based Magnetic Chemiluminescence Enzyme Immunoassay for Serological Diagnosis of Coronavirus Disease 2019. The Journal of Infectious Diseases. 2020. https://doi.org/10. 1093/infdis/jiaa243.

76. Vashist SK. In vitro diagnostic assays for COVID-19: recent advances and emerging trends. Diagnostics. 2020;10:202. https://doi. org/10.3390/diagnostics10040202.

77. To K-WT, Tsang T-YO, Leung WS, Tam AR, Wu TC, Lung DC, et al. Temporal profiles of viral load in posterior oropharyngeal saliva samples and serum antibody responses during infection by SARS-CoV-2: an observational cohort study. Lancet Infect Dis. 2020;20:565-74.

78. Lin D, Liu L, Zhang M, Hu Y, Yang Q, Guo J, Dai Y, et al. Evaluations of the serological test in the diagnosis of 2019 novel coronavirus (SARS-CoV-2) infections during the COVID-19 outbreak." European Journal of Clinical Microbiology \& Infectious Diseases 2020;1-7. https://doi.org/10.1007/s10096-020-03978-6.

79. Zhang P, Gao Q, Wang T, Ke Y, Mo F, Jia R, et al. Evaluation of recombinant nucleocapsid and spike proteins for serological diagnosis of novel coronavirus disease 2019 [COVID-19]. MedRxiv. 2020. https://doi.org/10.1101/2020.03.17.20036954.

80. Zhong L, Chuan J, Gong B, Shuai P, Zhou Y, Zhang Y, et al. Detection of serum IgM and IgG for COVID-19 diagnosis. Sci China Life Sci. 2020;63:777-80.

81. Scott A. Is a reagents shortage delaying European COVID-19 testing? https://cen.acs.org/analytical-chemistry/diagnostics/reagentsshortage-delaying-European-COVID/98/i13. Accessed 30 Apr 2020.

82. Li Z, Yi Y, Luo X, Xiong N, Liu Y, Li S, et al. Development and clinical application of a rapid IgM-IgG combined antibody test for SARS-CoV-2 infection diagnosis. J Med Virol. 2020. https://doi. org/10.1002/jmv.25727.

83. Xiang J, Yan M, Li H, Liu T, Lin C, Huang S, et al. Evaluation of enzyme-linked immunoassay and colloidal goldimmunochromatographic assay kit for detection of novel coronavirus [SARS-Cov-2] causing an outbreak of pneumonia [COVID19]. medRxiv. 2020. https://doi.org/10.1101/2020.02.27. 20028787.

84. Chen Z, Zhang Z, Zhai X, Li Y, Lin L, Zhao H, et al. Rapid and sensitive detection of anti-SARS-CoV-2 IgG using lanthanide- doped nanoparticles-based lateral flow immunoassay. Anal Chem. 2020;92:7226-31.

85. Norman M, Gilboa T, Ogata AF, Maley AM, Cohen L, Cai Y, et al. Ultra-sensitive high-resolution profiling of anti-SARS-CoV-2 antibodies for detecting early seroconversion in COVID-19 patients. medRxiv. 2020. https://doi.org/10.1101/2020.04.28.20083691.

86. Maache M, Komurian-Pradel F, Rajoharison A, Perret M, Berland J-L, Pouzol S, et al. False-positive results in a recombinant severe acute respiratory syndrome-associated coronavirus [SARS-CoV] nucleocapsid-based western blot assay were rectified by the use of two subunits [S1 and S2] of spike for detection of antibody to SARS-CoV. Clin Vaccine Immunol. 2006;13:409-14.

87. Okba N, Müller MA, Li W, et al. Severe Acute Respiratory Syndrome Coronavirus 2-Specific Antibody Responses in Coronavirus Disease Patients. Emerging Infectious Diseases. 2020;26(7):1478-1488. https://doi.org/10.3201/eid2607.200841.

88. Wang N, Li S-Y, Yang X-L, Huang H-M, Zhang Y-J, Guo H, et al. Serological evidence of bat SARS-related coronavirus infection in humans, China. Virol Sin. 2018;33:104-7.

89. Zhang W, Du R-H, Li B, Zheng X-S, Yang X-L, Hu B, et al. Molecular and serological investigation of 2019-NCoV infected patients: implication of multiple shedding routes. Emerg Microbes Infect. 2020;9:386-9.

90. WHO. Advice on the use of point-of-care immunodiagnostic tests for COVID-19. https://www.who.int/news-room/commentaries/ detail/advice-on-the-use-of-point-of-care-immunodiagnostic-testsfor-covid-19. Accessed 30 Apr 2020.

91. Farnsworth CW, Anderson NW. SARS-CoV-2 serology: much hype, little data. Clin Chem. 2020. https://doi.org/10.1093/ clinchem/hvaa107.

92. Infantino M, Damiani A, Gobbi FL, Grossi V, Lari B, Macchia D, et al. Serological assays for SARS-CoV-2 infectious disease: benefits, limitations and perspectives. Isr Med Assoc J. 2020;22:20310.

93. Petherick A. Developing antibody tests for SARS-CoV-2. Lancet. 2020;395:1101-2.

94. Giri B, Pandey B, Neupane B, Ligler FS. Signal amplification strategies for microfluidic immunoassays. TrAC Trends Anal Chem. 2016;79:326-34.

95. Lo S-J, Yang S-C, Yao D-J, Chen J-H, Tu W-C, Cheng C-M. Molecular-level dengue fever diagnostic devices made out of paper. Lab Chip. 2013;13:2686-92.

96. Yang T, Wang Y-C, Shen C-F, Cheng C-M. Point-of-care RNAbased diagnostic device for COVID-19. Diagnostics. 2020;10:165. https://oi.org/10.3390/diagnostics10030165.

97. Konrad R, Eberle U, Dangel A, Treis B, Berger A, Bengs K, et al. Rapid establishment of laboratory diagnostics for the novel coronavirus SARS-CoV-2 in Bavaria, Germany, February 2020. Euro Surveil. 2020;25:2000173. https://doi.org/10.2807/1560-7917.ES. 2020.25.9.2000173

Publisher's note Springer Nature remains neutral with regard to jurisdictional claims in published maps and institutional affiliations. 